УДК 539.3

DOI https://doi.org/10.26661/2413-6549-2021-1-08

\title{
КОНТАКТ ІЗ ЧАСТКОВИМ ПРОКОВЗУВАННЯМ МІЖ ПРУЖНИМ ПІВПРОСТОРОМ І КРУГОВИМ ШТАМПОМ ПІД ДІЄЮ НОРМАЛЬНОГО І ДОТИЧНОГО НАВАНТАЖЕНЬ
}

\author{
Стрелясв Ю. М. \\ кандидат фізико-математичних наук, \\ доиент кафедри фундаментальної математики \\ Запорізький національний університет \\ вул. Жуковського, 66, Запоріжжя, Україна \\ orcid.org/0000-0002-4400-7824 \\ strelkiny@gmail.com
}

Ключові слова: контактна задача, плоский штамп, дотичне навантаження, часткове проковзування, квазістатична задача, інтегральне рівняння, числовий розв'язок.
У статті представлено новий підхід до розв'язання квазістатичної просторової контактної задачі про фрикційну взаємодію жорсткого циліндричного штампа із плоскою основою та пружного півпростору, за умови послідовної дії на штамп монотонно зростаючих нормального та дотичного навантажень. Для врахування тертя ми використовували закон Кулона в класичній неспрощеній формі. Зони зчеплення і проковзування вважали заздалегідь невідомими і такими, що потрібно знайти. Процес навантажування моделювався скінченним числом станів рівноваги кроків навантажування. Контактну задачу зведено до послідовного розв'язання однотипних систем нелінійних граничних інтегральних рівнянь на кожному кроці дискретного процесу навантажування. Отримані інтегральні рівняння характеризуються тим, що їхній вигляд не залежить від конфігурації зон зчеплення і проковзування. Для складання таких рівнянь необхідно лише вказати канонічну обмежену плоску область, яка містить у собі невідомі ділянки контакту на усіх етапах процесу навантажування тіл. Для отримання наближених розв'язків цих систем виконано їх дискретизацію. Побудовано збіжні ітераційні процеси для числового розв'язання отриманих в результаті цієї дискретизації систем нелінійних скалярних рівнянь. За допомогою числових розрахунків, виконаних при різних значеннях дотичного переміщення штампа, дослідили процес зміни розподілів діючих на його основу питомих контактних зусиль. Також досліджено відносні переміщення контактуючих поверхонь та еволюцію форм і розмірів зон зчеплення i проковзування при поступовому збільшенні дотичного навантажування. Встановили, що з появою дотичної сили зона зчеплення втрачає симетрію і зміщується до переднього, відносно напрямку руху, краю штампа. При збільшенні зовнішнього дотичного зусилля площа зони зчеплення зменшується і стає нульовою за умови початку повного проковзування штампа по поверхні півпростору. Найбільші значення питомих дотичних контактних зусиль та відносних переміщень контактуючих поверхонь досягаються біля заднього, відносно напрямку руху, краю штампа. 


\title{
PARTIAL SLIP CONTACT BETWEEN ELASTIC HALF-SPACE AND CIRCULAR PUNCH UNDER NORMAL AND TANGENTIAL LOADS
}

\author{
Streliaiev Yu. M. \\ Candidate of Physical and Mathematical Sciences, \\ Associate Professor at the Department of Fundamental Mathematics \\ Zaporizhzhia National University \\ Zhukovskoho str., 66, Zaporizhzhia, Ukraine \\ orcid.org/0000-0002-4400-7824 \\ strelkiny@gmail.com
}

Key words: contact problem, flat punch, tangential loading, partial slip, quasi-static problem, integral equation, numerical solution.

\begin{abstract}
The article presents a new approach to solving the quasi-static spatial contact problem of interaction with friction between a rigid cylindrical punch with a flat base and an elastic half-space when monotonically increasing normal and tangential loads act on the punch sequentially. To account for friction, we used Coulomb's law in the classical form. We considered the stick and slip zones to be unknown in advance, which must be obtained. We simulated the loading process with a finite number of equilibrium states - loading steps. The contact problem is reduced to the sequential solution of similar systems of nonlinear boundary integral equations at each step of the discrete loading process. The resulting integral equations are characterized by the fact that their form does not depend on the configurations of the stick and slip zones. To compose such equations, it is only necessary to specify a canonical bounded flat region, which includes unknown areas of adhesion and slippage at all stages of loading the bodies. To obtain approximate solutions of these systems, they are discretized. Converging iterative processes are constructed for the numerical solution of the systems of nonlinear scalar equations obtained as a result of this discretization. Using numerical calculations performed for various values of the tangential displacement of the punch, we investigated the process of changing the distributions of contact tractions acting on its base. We also investigated the relative displacements of the contact surfaces and the evolution of the shapes and sizes of the stick and slip zones when the shear load gradually increases. We found that the stick zone loses symmetry and shifts towards the front (in the direction of the movement) edge of the punch when the tangential force begins to act. With an increase in the external tangential force, the area of the stick zone decreases and becomes zero when the punch begins to slide along the boundary of the elastic half-space. The maximum values of tangential contact stresses and relative displacements of the contact surfaces are achieved at the back edge of the punch.
\end{abstract}

Вступ. Задача про контактну взаємодію пружних тіл є важливою задачею сучасної механіки $\mathrm{i}$ має широке технічне застосування в машинобудуванні, будівельній механіці та інших галузях. Актуальність цієї задачі зумовлена питаннями міцності і зносостійкості різних механічних систем і конструкцій. Одним із факторів, що впливає на напруження у взаємодіючих елементах таких систем, $є$ тертя між контактуючими поверхнями цих елементів. При розв'язанні таких задач поверхня контакту і виникаючі на ній зони зчеплення і проковзування заздалегідь невідомі і можуть мати складну непрогнозовану форму. Ці обставини істотно обмежують можливості аналітичних методів і спонукають використовувати числові.
Аналіз стану проблеми. Дослідження часткового проковзування 3 тертям були розпочаті в роботах $[1 ; 2]$ і активно тривають по теперішній час. Огляди таких досліджень наведено в численних статтях [3-7] і книгах [8-13]. Особлива увага приділялась вивченню контактних задач для жорстких штампів 3 плоскою основою. Уперше контактна задача про вдавлювання прямокутного штампа в пружну півплощину при невідомій межі областей зчеплення і проковзування сформульована Л.О. Галіним [14]. Оскільки Галіну не вдалося знайти точний розв'язок, ця задача та ï аналоги розглядалися багатьма дослідниками. Огляд деяких аналітичних підходів до розв’язання задачі Галіна наве- 
дено в роботі [15]. Осесиметричний випадок контакту за умови повного зчеплення вивчений в роботах [16-19]. Нормальний контакт кругового штампа 3 пружним півпростором при наявності зчеплення і проковзування при монотонному і немонотонному навантажуваннях досліджено в роботах $[13 ; 20-24]$. Для випадку коли на штамп крім нормальної сили діє зсувна, за умови повного проковзування, В. I. Моссаковським в роботі [19] отримано наближений аналітичний розв'язок. Дотичний контакт плоского штампу і пружного півпростору за наявності зчеплення i проковзування вивчено мало.

Мета і завдання дослідження. Метою статті $\epsilon$ дослідження часткового проковзування 3 тертям між контактуючими поверхнями пружного півпростору і жорсткого циліндричного штампа 3 плоскою основою, що виникає в результаті послідовно діючих на штам нормального і дотичного навантажень. Для реалізації цієї мети необхідно знайти розподіли питомих контактних зусиль, відносні переміщення контактуючих поверхонь, конфігурації областей зчеплення і проковзування та проаналізувати еволюцію цих характеристик контакту в процесі зростання дотичного навантажування штампа.

Виклад основного матеріалу.

1. Система інтегральних рівнянь контактної задачі

Розглянемо квазістатичну просторову контактну задачі про взаємодію двох лінійно-пружних тіл при наявності кулонівського тертя [3] між ними. У разі, коли одне з тіл є абсолютно жорстким, вважатимемо його умовно пружним 3 нескінченним модулем Юнга. Вважатимемо також, що тіла допускають апроксимацію пружними півпросторами. Розглядатимемо процес навантажування як скінченне число $l$ послідовних станів рівноваги (кроків навантажування). Як показано в роботі [25], на кожному $i$-му кроці навантажування задача зводиться до розв'язання системи нелінійних інтегральних рівнянь такого вигляду:

$$
\left\{\begin{array}{c}
p_{1 i}(s)=h\left(p_{1 i}(s)-\tilde{E}\left(\sum_{j=1}^{3} A\left(p_{j i}\right)_{s}+\delta_{0}(s)+\Delta_{1 i}\right)\right) ; \\
p_{2 i}(s)=q\left(p_{2 i}(s)-\tilde{E}\left(\sum_{j=1}^{3} A\left(p_{j i}\right)_{s}+\tilde{\Delta}_{2 i}(s)\right)\right. \\
\left.p_{3 i}(s)-\tilde{E}\left(\sum_{j=1}^{3} A\left(p_{j i}\right)_{s}+\tilde{\Delta}_{3 i}(s)\right), \mu p_{1 i-1}(s)\right) ; \\
p_{3 i}(s)=q\left(p_{3 i}(s)-\tilde{E}\left(\sum_{j=1}^{3} A\left(p_{j i}\right)_{s}+\tilde{\Delta}_{3 i}(s)\right)\right. \\
\left.p_{2 i}(s)-\tilde{E}\left(\sum_{j=1}^{3} A\left(p_{j i}\right)_{s}+\tilde{n}_{2 i}(s)\right), \mu p_{1 i-1}(s)\right)
\end{array}\right.
$$

де $i=\overline{1, l} ; \Omega$ - обмежена плоска область, яка містить невідому ділянку контакту і розташована у загальній для тіл дотичній площині $\Pi ; s-$ довільна точка області $\Omega ; p_{1 i}(s), p_{2 i}(s), p_{3 i}(s)-$ невідомі функції, що задають розподіли в області $\Omega$ нормальної і дотичних компонент питомого контактного навантаження на $i$-му кроці; $\Delta_{1 i}(s), \Delta_{2 i}(s), \Delta_{3 i}(s)$ - задані функції, що визначають умови навантажування тіл; $\delta_{0}(s)-$ функція, що задає початковий зазор між тілами; $\tilde{E}-$ довільне додатне число; $\mu>0$ - коефіцієнт тертя.

Оператори впливу поверхневих напружень на поверхневі пружні переміщення $A_{k j}$, що входять в (1), задають співвідношеннями

$$
A_{k j}(x)_{s}=\int_{\Omega} K_{k j}\left(s, s^{\prime}\right) \cdot x\left(s^{\prime}\right) d s^{\prime},(k, j=\overline{1,3}) .
$$

Ядра цих операторів $K_{k j}\left(s, s^{\prime}\right)$ визначають 3 розв'язків Буссінеска-Черруті [8].

Функції $\tilde{\Delta}_{2 i}(s), \tilde{\Delta}_{2 i}(s)$, що входять в (1), визначають 3 наступних співвідношень [25]:

$$
\begin{aligned}
& \tilde{\Delta}_{2 i}(s)=\Delta_{2 i}(s)-\sum_{j=1}^{3} A_{2 j}\left(p_{j i-1}\right)_{s}-\Delta_{2 i-1}(s), \\
& \tilde{\Delta}_{3 i}(s)=\Delta_{3 i}(s)-\sum_{j=1}^{3} A_{3 j}\left(p_{j i-1}\right)_{s}-\Delta_{3 i-1}(s) .
\end{aligned}
$$

Функції $h$ і $q$, що входять в (1), мають такий вигляд:

$$
\begin{gathered}
h(x)=\left\{\begin{array}{l}
x, \text { якщо } x \geq 0 ; \\
0, \text { якщо } x<0 ;
\end{array}\right. \\
q(x, y, z)=\left\{\begin{array}{c}
x, \text { якщо } \sqrt{x^{2}+y^{2}} \leq z ; \\
x \cdot \frac{z}{\sqrt{x^{2}+y^{2}}}, \text { якщо } \sqrt{x^{2}+y^{2}}>z .
\end{array}\right.
\end{gathered}
$$

Знаходження аналітичного розв'язку системи (1) є складним, тому для розв'язання цієї системи доцільно застосовувати числові методи, засновані на дискретизації інтегральних рівнянь 3 подальшим застосуванням ітераційних методів.

2. Метод числового розв'язання системи (1)

Задамо область $\Omega$ у вигляді відкритого квадрата зі сторонами, паралельними осям декартової системи координат $x O y$, яку введено на площині П. Розіб'ємо цю область на $n^{2}$ квадратних рівних областей $\omega_{1}^{n}, \omega_{2}^{n}, \ldots, \omega_{n^{2}}^{n}$, орієнтованих подібно $\Omega$. Вважаючи, що невідомі функції $p_{1 i}(s), p_{2 i}(s), p_{3 i}(s)$ приймають на кожному граничному елементі $\omega_{k}^{n}$ сталі значення $x_{3 k-2 i}, x_{3 k-1 i}$, $x_{3 k i}$, зведемо знаходження наближеного розв'язку системи (1) до розв'язання на кожному $i$-му кроці навантажування системи $3 n^{2}$ нелінійних скалярних рівнянь: 


$$
\left\{\begin{aligned}
x_{3 k-2 i} & =h\left(x_{3 k-2 i}-\tilde{E} \cdot\left(\sum_{j=1}^{3 n^{2}} a_{3 k-2 j} \cdot x_{j i}-b_{3 k-2 i}\right)\right) \\
x_{3 k-1 i} & =q\left(x_{3 k-1 i}-\tilde{E} \cdot\left(\sum_{j=1}^{3 n^{2}} a_{3 k-1 j} \cdot x_{j i}-b_{3 k-1 i}\right), x_{3 k i}-\right. \\
& \left.-\tilde{E} \cdot\left(\sum_{j=1}^{3 n^{2}} a_{3 k j} \cdot x_{j i}-b_{3 k i}\right), \mu \cdot x_{3 k-2 i-1}\right) ; \\
x_{3 k i} & =q\left(x_{3 k i}-\tilde{E} \cdot\left(\sum_{j=1}^{3 n^{2}} a_{3 k j} \cdot x_{j i}-b_{3 k i}\right), x_{3 k-1 i}-\right. \\
& \left.-\tilde{E} \cdot\left(\sum_{j=1}^{3 n^{2}} a_{3 k-1 j} \cdot x_{j i}-b_{3 k-1 i}\right), \mu \cdot x_{3 k-2 i-1}\right)
\end{aligned}\right.
$$

У системі (7) числові параметри $a_{k j} \epsilon$ елементами матриці податливості взаємодіючих тіл, а $b_{k i}$ визначають умови навантаження взаємодіючих тіл на $i$-му кроці навантажування $[25 ; 26]$.

Наближений розв'язок системи (7) при кожному фіксованому $i$ шукатимемо за допомогою методу простої ітерації, використовуючи наступний ітераційний процес:

$$
\left\{\begin{array}{c}
\left(x_{1 i}^{(0)}, x_{2 i}^{(0)}, \ldots, x_{3 n^{2} i}^{(0)}\right) \in R^{3 n^{2}} ; \\
x_{3 k-2 i}^{(m+1)}=h\left(x_{3 k-2 i}^{(m)}-\tilde{E} \cdot\left(\sum_{j=1}^{3 n^{2}} a_{3 k-2 j} \cdot x_{j i}^{(m)}-b_{3 k-2 i}\right)\right) ; \\
x_{3 k-1 i}^{(m+1)}=q\left(x_{3 k-1 i}^{(m)}-\tilde{E} \cdot\left(\sum_{j=1}^{3 n^{2}} a_{3 k-1 j} \cdot x_{j i}^{(m)}-b_{3 k-1 i}\right), x_{3 k i}^{(m)}-\right. \\
\left.-\tilde{E} \cdot\left(\sum_{j=1}^{3 n^{2}} a_{3 k j} \cdot x_{j i}^{(m)}-b_{3 k i}\right), \mu \cdot x_{3 k-2 i-1}\right) ; \\
x_{3 k i}^{(m+1)}=q\left(x_{3 k i}^{(m)}-\tilde{E} \cdot\left(\sum_{j=1}^{3 n^{2}} a_{3 k j} \cdot x_{j i}^{(m)}-b_{3 k i}\right), x_{3 k-1 i}^{(m)}-\right. \\
\left.-\tilde{E} \cdot\left(\sum_{j=1}^{3 n^{2}} a_{3 k-1 j} \cdot x_{j i}^{(m)}-b_{3 k-1 i}\right), \mu \cdot x_{3 k-2 i-1}\right) ;
\end{array}\right.
$$

У роботі [27], за допомогою принципу стискаючих відображень, доведено, що ітераційний процес (8) збігається на кожному $i$-му кроці навантажування при будь-якому виборі початкового наближення $\left(x_{1 i}^{(0)}, x_{2 i}^{(0)}, \ldots, x_{3 n^{2} i}^{(0)}\right) \in R^{3 n^{2}} \quad$ за умови $\tilde{E}<\left(\max _{1 \leq i \leq 3 n^{2}} \sum_{j=1}^{3 n^{2}}\left|a_{i j}\right|\right)^{-1}$. При послідовному розв'язанні серії систем (7) за допомогою ітераційного процесу (8) обиратимемо наближений розв'язок системи (7), отриманий на $(i-1)$-му кроці навантажування, за початкове наближення на $i$-му кроці. При $i=1$ будемо вважати вектор початкового наближення нульовим.

\section{3. Числові результати}

Запропонований підхід застосували до розв'язання контактної задачі про взаємодію жорсткого циліндричного штампа 3 плоскою круговою основою і пружного півпростору при послідовній дії на штамп нормального і дотичного навантажень. Для розрахунків використовували такі вихідні дані: радіус основи штампа $R=0,005 \mathrm{~m}$; для пружного півпростору обрали коефіцієнт Пуассона $v=0,3$ і модуль Юнга $E=210000$ МПа; коефіцієнт тертя $\mu=0,25$.

Декартова система координат $O x y z$ вводилась так, щоб пружний півпростір визначався нерівністю $z \leq 0$, а початок координат співпадав 3 центром основи штампа, яка в ненавантаженому стані належить площині $z=0$ (рис. 1).

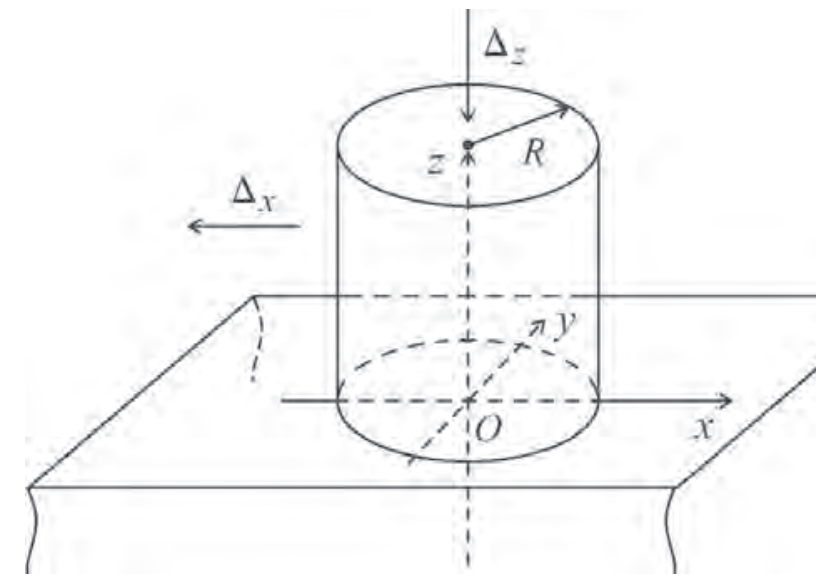

Рис. 1. Схема контакту

Процес навантажування здійснювався за $2 l$ кроків у відповідності 3 наступним законом зміни нормального $\Delta_{1 i}$ і дотичних $\Delta_{2 i}, \Delta_{3 i}$ переміщень штампа у напрямах осей $O z i O x, O y$ відповідно:

$$
\begin{gathered}
\Delta_{1 i}=\left\{\begin{array}{c}
\frac{-\Delta_{z} \cdot i}{l}, \text { якщо } 1 \leq i \leq l ; \\
-\Delta_{z}, \text { якщо } l+1 \leq c ;
\end{array}\right. \\
\Delta_{2 i}=\left\{\begin{array}{c}
0, \text { якщо } 1 \leq i \leq l ; \\
\frac{-\Delta_{x} \cdot(i-l)}{l}, \text { якщо } l+1 \leq i \leq 2 l ;
\end{array}\right. \\
\Delta_{3 i}=0,1 \leq i \leq 2 l .
\end{gathered}
$$

Тут $\Delta_{z}$ i $\Delta_{x}$ - максимальні значення абсолютних величин кінцевих зсувів штампа в напрямах осей $O z$ і $O x$. Така історія навантажування відповідає початковому монотонному вдавлюванню штампа в півпростір на величину заглиблення $\Delta_{z}$ 3 подальшим його поступово зростаючим дотичним зсувом на $\Delta_{x}$ при фіксованому значенні $\Delta_{z}$.

Для числових розрахунків використовували поверхневу сітку з $81 \times 81=6561$ квадратних граничних елементів. Значення $l$ в процесі навантажування (9) обирали рівним 20. Нижче наведені 
результати, отримані на кожному 3 двох етапів навантаження.

3.1. Нормальне навантажування. Для абсолютної величини нормального зміщення штампа $\Delta_{z}$ обирали значення $4 \cdot 10^{-5}$ м . На рис. 2 подано отримані на останньому кроці першого етапу навантажування ( $i=l$ в формулах (9)) розподіли нормальних і дотичних контактних зусиль, що діють на основу штампа уздовж осі $O x$.

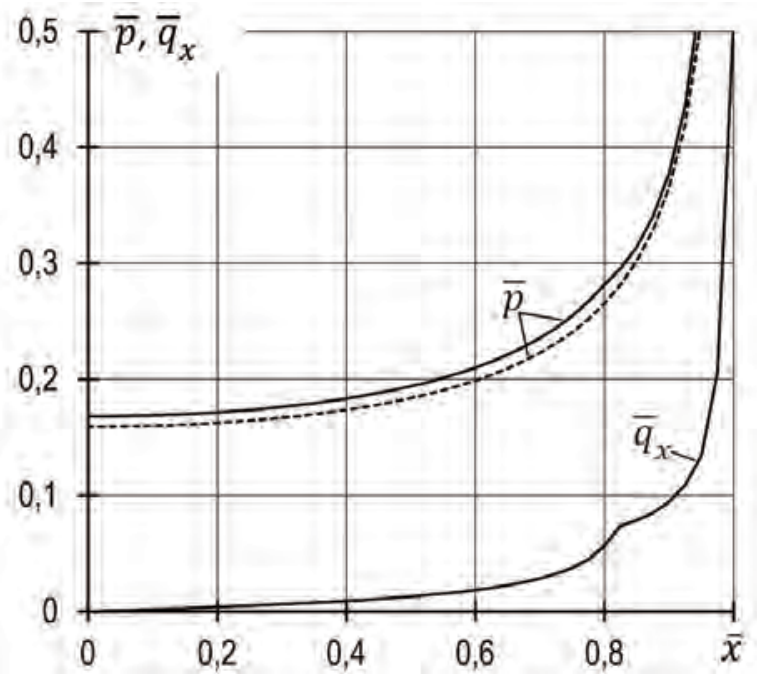

Рис. 2. Розподіли питомих контактних зусиль

Тут $\bar{x}=x / R \quad-$ безрозмірна координата; $\bar{p}=\frac{R^{2}}{P} \cdot p_{1 l}(\bar{x}, 0), \quad \bar{q}_{x}=\frac{R^{2}}{P} \cdot p_{2 l}(\bar{x}, 0) \quad$ - безрозмірні нормальні і дотичні питомі контактні зусилля. Пунктирна лінія відповідає відомому розподілу контактного тиску $\bar{p}=\frac{1}{2 \pi}\left(1-(\bar{x})^{2}\right)^{-\frac{1}{2}}$ за відсутності тертя. Значення абсолютної величини нормальної сили $P=\int_{\Omega} p(s) d s$, що відповідає переміщенню штампа $\Delta_{z}$, склало приблизно 94кН. Отримали відносний розмір зони зчеплення $R_{1} / R \approx 0,8196$, нормалізовану осадку штампа $\bar{\delta}=\left(\frac{E R}{P(1+v)}\right) \cdot \Delta_{z} \approx 0,3427$.

3.2. Дотичне навантажування. Для дослідження зміни параметрів контакту, за монотонного зростання дотичного навантаження при сталому значенні безрозмірного нормального зміщення штампа $\bar{\Delta}_{z}=\Delta_{z} / R=0,008$, дотичному зміщенню $\bar{\Delta}_{x}=\Delta_{x} / R$ надавали послідовно зростаючі значення в діапазоні від 0 до 0,008. На рис. 3 подано залежності від $\bar{\Delta}_{x}$ безрозмірних нормальної сили $P^{*}=P /\left(E R^{2}\right)$ та дотичної $Q^{*}=Q /\left(E R^{2}\right)$.

Розподіли діючих на штамп уздовж осі $O x$ питомих дотичних зусиль $\bar{q}_{x}=\frac{R^{2}}{P} \cdot p_{22 l}(\bar{x}, 0)$

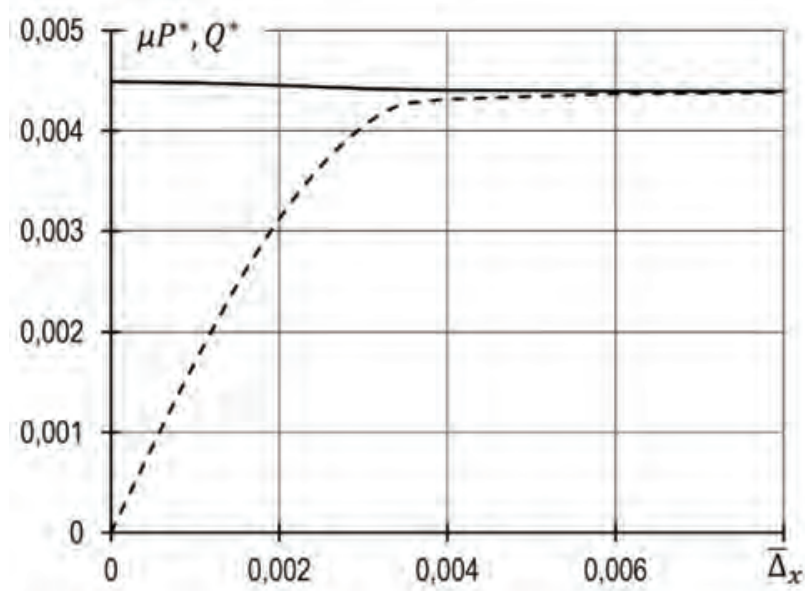

Рис. 3. Залежність нормальної і дотичної сил від дотичного зсуву

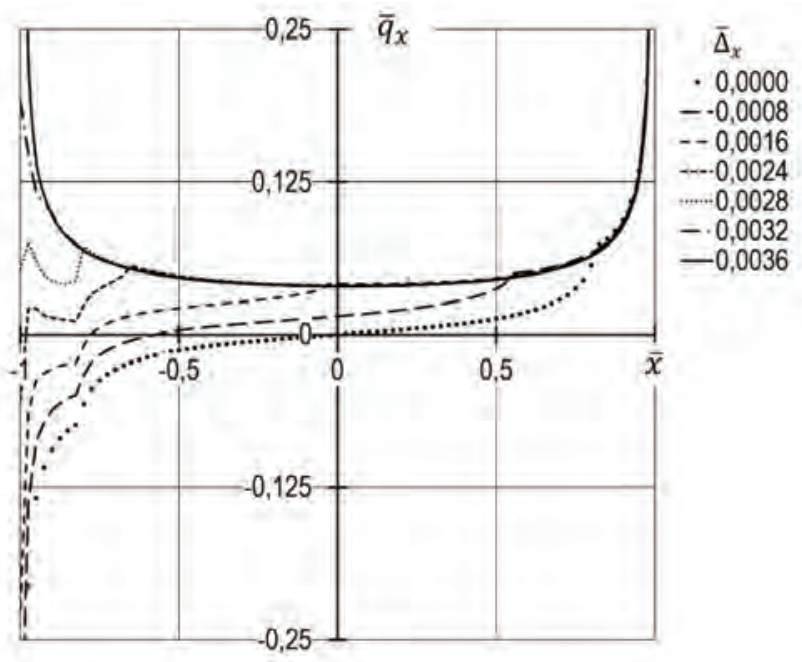

Рис. 4. Розподіли питомих дотичних контактних зусиль

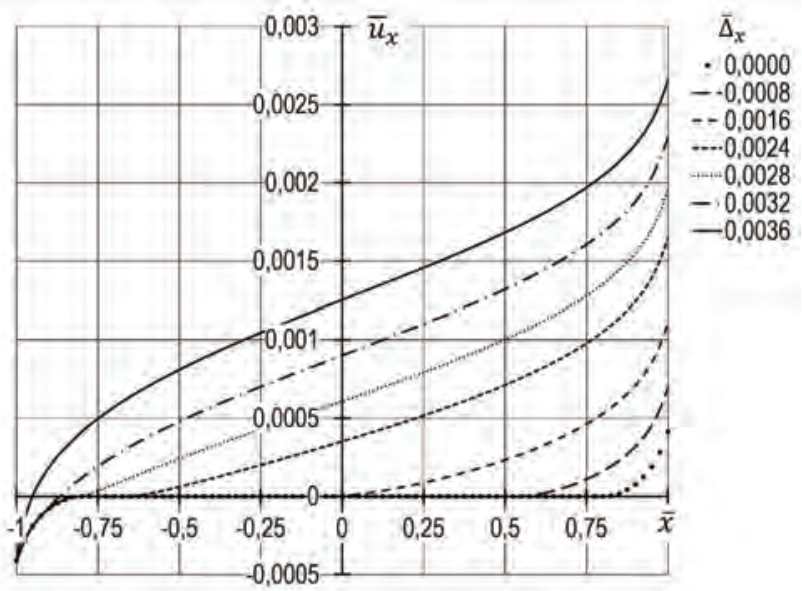

Рис. 5. Залежність відносних дотичних переміщень контактуючих поверхонь від координати 
за різних значень дотичного зсуву $\bar{\Delta}_{x}$ від 0 до 0,0036 подано на рис. 4 .

На рис. 5 подано відповідні залежності відносних дотичних переміщень контактуючих поверхонь $\bar{u}_{x}=u_{x} / R$ від координати $\bar{x}$. Тут $u_{x}-$ переміщення точок поверхні півпростору, розташованих на осі $O x$, відносно протилежних точок основи штампа.

Конфігурації зон зчеплення та проковзування, що відповідають різним значенням $\bar{\Delta}_{x}$, подано на рис. 6. Тут темно-сірим кольором зображено зону зчеплення, світло-сірим - зону проковзування.

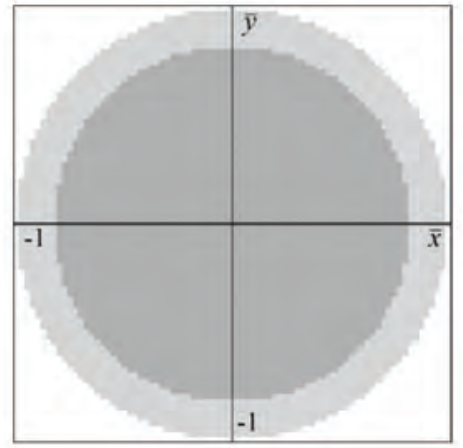

a) $\bar{\Delta}_{x}=0$

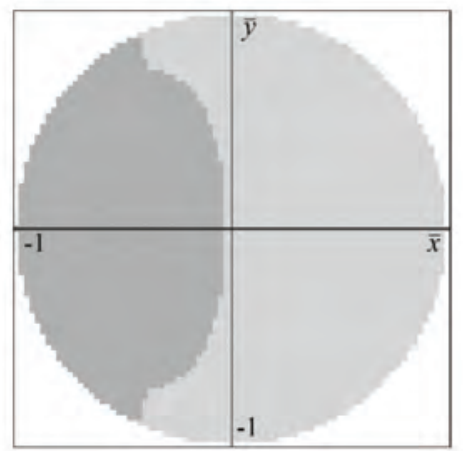

в) $\bar{\Delta}_{x}=0,0016$

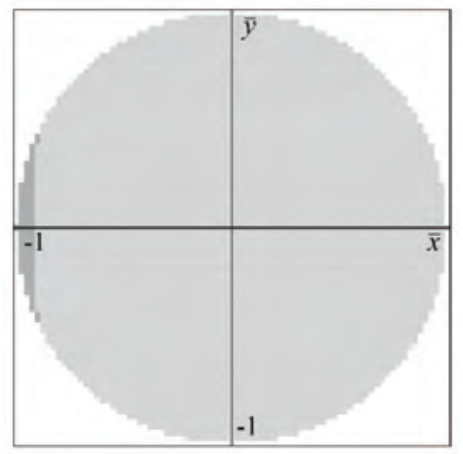

д) $\bar{\Delta}_{x}=0,0032$
Обговорення результатів. Аналіз отриманих результатів показує, що при нормальному навантаженні штампа (за рахунок його переміщення $\bar{\Delta}_{\mathrm{z}}=0,008$ ) в області контакту утворюється центральна кругова область зчеплення і прилегла до краю кільцева зона проковзування. Отримані розподіли нормальних і дотичних контактних зусиль (рис. 2), а також відносний радіус зони зчеплення i осадка штампа добре узгоджуються 3 аналітичним розв'язком осесиметричного аналога задачі Галіна [13; 22]. Відносна помилка порівнюваних значень не перевищує $2 \%$.

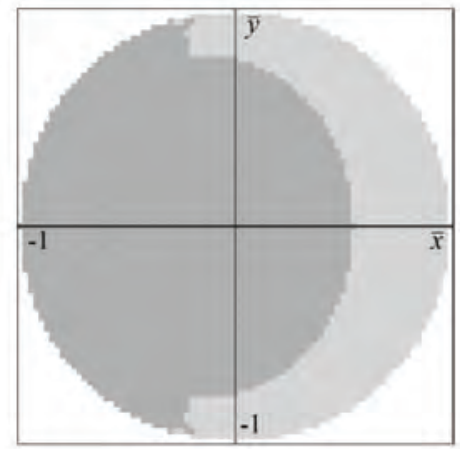

б) $\bar{\Delta}_{x}=0,0008$

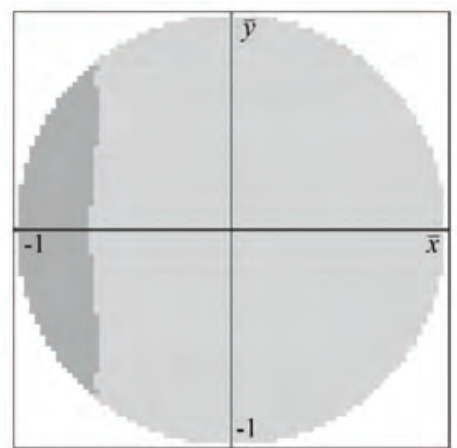

z) $\bar{\Delta}_{x}=0,0024$

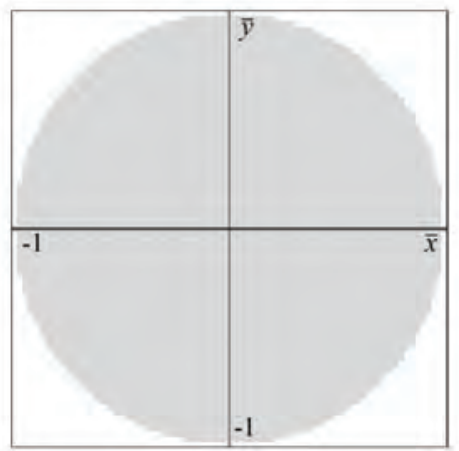

e) $\bar{\Delta}_{x}=0,0036$

Рис. 6. Конфігурації зон зчеплення та проковзування при різних значеннях дотичного переміщення штампа $\bar{\Delta}_{x}$ 
За умови, коли при фіксованому значенні $\bar{\Delta}_{z}$ на штамп починає діяти монотонно зростаюча дотична сила, що спричиняє його переміщення $\bar{\Delta}_{x}$ (в напрямку, протилежному додатному напрямку осі $O x$ ), зона зчеплення втрачає центральну симетрію, іiі «ліва» межа відразу ж охоплює область, прилеглу до краю основи штампа, а «права» зміщується в напрямку переміщення штампа (рис. 6). Як видно 3 рис. 3 , зі збільшенням значення $\bar{\Delta}_{x}$ дотична сила $Q^{*}$ зростає за нелінійним законом, при цьому нормальна сила $P^{*}$ близька до сталої (спостерігається несуттєве зменшення сили $P^{*}$, приблизно на $2 \%$ від іiі максимального значення при $\left.\bar{\Delta}_{x}=0\right)$. При $\bar{\Delta}_{x} \geq 0,0036$ графіки $P^{*}$ і $Q^{*}$ починають асимптотично зближуватись, що відповідає початку повного проковзування штампа по поверхні півпростору (рис. 6 e). При $\bar{\Delta}_{x}=0,006$ відношення $Q^{*} / P^{*}$ дорівнює приблизно 0,0248 , що не більше ніж на $1 \%$ відхиляється від заданого коефіцієнта тертя $\mu=0,25$. Цей результат підтверджується також аналізом графіків дотичних контактних зусиль і відносних дотичних переміщень контактуючих поверхонь (суцільні лінії на рис. 4, 5). Дотичні контактні зусилля в цьому випадку прямо пропорційні контактним тискам, а відносні переміщення відмінні від їх значень, досягнутих на нормальному етапі, та досягають максимальних значень біля правого краю основи штампа.
Висновки. Методом нелінійних крайових інтегральних рівнянь отримано наближений розв'язок квазістатичної контактної задачі про фрикційну взаємодію жорсткого циліндричного штампа 3 плоскою основою та пружного півпростору, за умови послідовної дії на штамп монотонно зростаючих нормального та дотичного навантажень.

За допомогою числових розрахунків при різних значеннях дотичного переміщення штампа досліджено процес зміни розподілів діючих на його основу питомих контактних зусиль, відносних переміщень контактуючих поверхонь, форм i розмірів зон зчеплення i проковзування при поступовому збільшенні дотичного навантажування. Встановлено, що 3 початком дії дотичної сили зона зчеплення, що утворилась на нормальному етапі навантажування, втрачає центральну симетрію і зміщується до переднього, відносно напрямку руху, краю штампа. При монотонному зростанні зовнішнього дотичного зусилля площа зони зчеплення зменшується і стає нульовою за умови початку повного проковзування штампа по поверхні півпростору. Відносні переміщення контактуючих поверхонь при цьому зростають при наближенні до заднього, відносно напрямку руху, краю штампа, біля якого вони приймають максимальні значення. Порівняння отриманих результатів з відомими свідчить про їх коректність.

\section{ЛITEPATУРA}

1. Cattaneo C. Sul contatto di due corpi elastici: distribuzione locale degli stozzi. Rend. Dell'Academia nazionale dei Lincei. 1938. 27(6). P. 342-348, 434-436, 474-478.

2. Mindlin R.D. Compliance of elastic bodies in contact. Trans. ASME, J. Appl. Mech. 1949. 16(3). P. 259-268.

3. Kalker J.J. A survey of the mechanics of contact between solid bodies. ZAMM. 1977. 57(5). T3-T17.

4. Hills D.A., Urriolagoitia Sosa G. Origins of partial slip in fretting - a review of known and potential solutions. The Journal of Strain Analysis for Engineering Design. 1999 34(3). P. 175-181.

5. Barber J.R., Ciavarella M. Contact mechanics. International Journal of Solids and Structures. 2000. 37(1-2). P. 29-43.

6. Goryacheva I.G., Martynyak R.M. Contact problems for textured surfaces involving frictional effects. Proceedings of the Institution of Mechanical Engineers. Part J: Journal of Engineering Tribology. 2014. 228(7). P. 707-716.

7. Andresen H., Hills D.A. A review of partial slip solutions for contacts represented by half-planes including bulk tension and moments. Tribology International. 2020. 143. 106050

8. Джонсон К.Л. Механика контактного взаимодействия. Москва: Мир, 1989. 510 с.

9. Hills D.A., Nowell D., Sackfield A. Mechanics of Elastic Contact. Oxford: Butterworth-Heinemann, 1993.

10. Острик В.И., Улитко А.Ф. Метод Винера-Хопфа в контактных задачах теории упругости. Киев: Наук. Думка, 2006. 328 с.

11. Popov V.L. Contact Mechanics and Friction. Physical Principles and Applications. Berlin: Springer, 2017.

12. Barber J.R. Contact mechanics. Dordrecht, TheNetherlands: Springer, 2018.

13. Острик B.I. Метод факторизації та його узагальнення у змішаних задачах теорії пружності. Київ : ВПЦ «Київський університет», 2018. 480 с.

14. Галин Л. А. Вдавливание штампа при наличии трения и сцепления. Прикладная математика $u$ механика. 1945. Т. 9, вып. 5. С. 413-424.

15. Zhupanska O.I. On the analytical approach to Galin's stick-slip problem. A survey. Journal of Elasticity. 90(3). P. 315-333.

16. Моссаковский В. И. Сжатие упругих тел в условиях сцепления (осесимметричный случай). Прикладная математика и механика. 1963. Т. 27, вып. 3. С. 418-427. 
17. Goodman L.E. Contact stress analysis of normally loaded rough spheres. J. Appl. Mech. 1962. 29(3). P. 515-522.

18. Spence D. Self-similar solutions to adhesive contact problems with incremental loading. Proc. Roy. Soc. 1968. A 305. P. 55-80.

19. Моссаковский В.И., Качаловская Н.Е., Голикова С.С. Контактные задачи математической теории упругости. Киев: Наукова Думка, 1985. 175 с.

20. Spence D. The Hertz contact problem with finite friction. Journal of elasticity. 1975. 5(3). P. 297-319.

21. Turner J. R. The frictional unloading problem on linear elastic half-space. IMA Journal of Applied Mathematics. 1979. Vol. 24. P. 439-469.

22. Острик В.И. Контактное взаимодействие кругового штампа с упругим полупространством при наличии трения и сцепления. Теор. и прикл. механика. 2011. 2(48). С. 22-28.

23. Стреляєв Ю. М., Клименко М. І., Стреляєв О. Ю. Контакт плоского циліндричного штампа з пружним півпростором при немонотонному навантажуванні з урахуванням тертя. Вісник Запорізького національного університету. Фізико-математичні науки. 2018. № 2. С. 142-151.

24. Стреляєв Ю.М., Тітова О.О. Контакт зі зчепленням і проковзуванням циліндричного плоского штампа з заокругленим краєм та пружного півпростору. Вісник Запорізького наиіонального університету. Фізико-математичні науки. 2020. № 1. С. 86-92.

25. Стреляев Ю. М. Метод нелинейных граничных интегральных уравнений для решения квазистатической контактной задачи о взаимодействии упругих тел при наличии кулонова трения. Becmник Самарского государственного технического университета. Серия Физико-математические науки. 2016. Т. 20, № 2. С. 306-327.

26. Александров А. И., Стреляев Ю. М. Метод нелинейных граничных интегральных уравнений для контактных задач теории упругости. Восточно-Европейский журнал передовых технологий. 2014. 3(7). C. 36-40.

27. Стреляев Ю.М. Решение квазистатической контактной задачи теории упругости с учетом трения. Вісник ЗНУ. Математичне моделювання і прикладна механіка. Фізико-математичні науки. 2014. № 2. C. 161-172.

\section{REFERENCES}

1. Cattaneo, C. (1938). Sul contatto di due corpi elastici: distribuzione locale degli stozzi. Rend. Dell'Academia nazionale dei Lincei, 27(6), 342-348, 434-436, 474-478.

2. Mindlin, R.D. (1949). Compliance of elastic bodies in contact. Trans. ASME, J. Appl. Mech., 16(3), 259-268.

3. Kalker, J.J. (1977). A survey of the mechanics of contact between solid bodies. ZAMM, 57(5), T3-T17.

4. Hills, D.A. \& Urriolagoitia Sosa, G. (1999). Origins of partial slip in fretting - a review of known and potential solutions. The Journal of Strain Analysis for Engineering Design, 34(3), 175-181.

5. Barber, J.R. \& Ciavarella, M. (2000). Contact mechanics. International Journal of Solids and Structures, $37(1-2), 29-43$.

6. Goryacheva, I.G. \& Martynyak, R.M. (2014). Contact problems for textured surfaces involving frictional effects. Proceedings of the Institution of Mechanical Engineers, Part J: Journal of Engineering Tribology, 228(7), 707-716.

7. Andresen, H. \& Hills, D.A. (2020). A review of partial slip solutions for contacts represented by halfplanes including bulk tension and moments. Tribology International, 143, 106050.

8. Johnson, K.L. (1985). Contact mechanics. Cambridge: Cambridge University Press.

9. Hills, D.A., Nowell, D. \& Sackfield, A. (1993). Mechanics of Elastic Contact. Oxford: Butterworth-Heinemann.

10. Ostryk, V.I. \& Ulitko, A.F. (2006). Metod Vinera-Hopfa v kontaktnyh zadachah teorii uprugosti [The Wiener-Hopf Method in Contact Problems of Elasticity Theory]. Kyiv: Naukova Dumka. (in Ukrainian).

11. Popov, V.L. (2017). Contact Mechanics and Friction. Physical Principles and Applications. Berlin: Springer.

12. Barber. J.R. (2018). Contact mechanics. Dordrecht, TheNetherlands: Springer.

13. Ostryk, V.I. (2018). Metod faktoryzatsii ta yoho uzahalnennia u zmishanykh zadachakh teorii pruzhnosti [Factorization method and its generalization in mixed problems of elasticity theory]. Kyiv: VPC «Kyivskyi universytet». (in Ukrainian).

14. Galin, L.A. (1945). Indentation of a punch in the presence of friction and adhesion. Prikl. Mat. Mekh., 9(5), 413-424. 
15. Zhupanska, O.I. (2008). On the analytical approach to Galin's stick-slip problem. A survey. Journal of Elasticity, 90(3), 315-333.

16. Mossakovskii, V.I. (1963). Compression of elastic bodies under conditions of adhesion (axisymmetric case). Journal of Applied Mathematics and Mechanics, 27(3), 630-643.

17. Goodman, L.E. (1962). Contact stress analysis of normally loaded rough spheres. J. Appl. Mech., 29(3), 515-522.

18. Spence D. (1968). Self-similar solutions to adhesive contact problems with incremental loading. Proc. Roy. Soc., A 305, 55-80.

19. Mossakovskii, V.I., Kachalovskaja, N.E. \& Golikova, S.S. (1985). Kontaktnye zadachi matematicheskoj teorii uprugosti [Contact problems of the mathematical theory of elasticity]. Kiev: Naukova Dumka. (in Russian).

20. Spence, D. (1975). The Hertz contact problem with finite friction. Journal of elasticity, 5(3), 297-319.

21. Turner, J. R. (1979).The frictional unloading problem on linear elastic half-space. IMA Journal of Applied Mathematics, 24, 439-469.

22. Ostrik, V.I. (2011). Kontaktnoe vzaimodejstvie krugovogo shtampa s uprugim polu-prostranstvom pri nalichii trenija i sceplenija [Contact interaction of circular stamp with elastic half-space with regard for friction and adhesion] Teor. i prikl. mehanika, 2(48), 22-28. (in Russian).

23. Streliaiev, Yu.M., Klymenko, M.I., \& Streliaiev, O.Yu. (2018). Kontakt ploskoho tsylindrychnoho shtampa $\mathrm{z}$ pruzhnym pivprostorom pry nemo-notonnomu navantazhuvanni z urakhuvanniam tertia [Contact with friction of a flat cylindrical punch with an elastic half-space under nonmonotonic loading]. Visnyk of Zaporizhzhya National University. Physical and mathematical Sciences, 2, 142-151. (in Ukrainian).

24. Streliaiev, Yu.M. \& Titova, O.O. (2020). Kontakt zi zcheplenniam i prokovzuvanniam tsylindrychnoho ploskoho shtampa z zaokruhlenym kraiem ta pruzhnoho pivprostoru [Stick-slip contact of the cylindrical flat punch with a rounded edge and elastic half-space]. Visnyk of Zaporizhzhya National University. Physical and mathematical Sciences, 1, 86-92. (in Ukrainian).

25. Streliaiev, Yu. M. (2016). Metod nelinejnyh granichnyh integral'nyh uravnenij dlja reshenija kvazi-staticheskoj kontaktnoj zadachi o vzaimodejstvii uprugih tel pri nalichii kulonova trenija [A nonlinear boundary integral equations method for the solving of quasistatic elastic contact problem with Coulomb friction]. Vestn. Samar. Gos. Tekhn. Univ., Ser. Fiz. -Mat. Nauki [J. Samara State Tech. Univ., Ser. Phys. Math. Sci.], 20(2), 306-327. (in Russian).

26. Alexandrov, A., \& Streliaiev, Y. (2014). Metod nelinejnyh granichnyh integral'nyh uravnenij dlja kontaktnyh zadach teorii uprugosti [Nonlinear boundary integral equation's method for elastic contact problems]. Eastern-European Journal of Enterprise Technologies, 3(7), 36-40. (in Russian).

27. Streliaiev, Y.M. (2014). Reshenie kvazistaticheskoj kontaktnoj zadachi teorii uprugosti s uchetom trenija [Solution of the quasistatic contact problem of elasticity with friction]. Visnyk of Zaporizhzhya National University. Physical and mathematical Sciences, 2, 161-172. (in Russian). 